\title{
Analysis of Price Stackelberg Duopoly Game with Bounded Rationality
}

\author{
Lian Shi, ${ }^{1}$ Yun Le, ${ }^{1}$ and Zhaohan Sheng ${ }^{1,2}$ \\ ${ }^{1}$ School of Economics and Management, Tongji University, Shanghai 200092, China \\ ${ }^{2}$ School of Management Science and Engineering, Nanjing University, Nanjing 210093, China \\ Correspondence should be addressed to Yun Le; yunle@kcpm.com.cn
}

Received 18 October 2013; Revised 9 January 2014; Accepted 9 January 2014; Published 17 February 2014

Academic Editor: Stepan A. Tersian

Copyright (c) 2014 Lian Shi et al. This is an open access article distributed under the Creative Commons Attribution License, which permits unrestricted use, distribution, and reproduction in any medium, provided the original work is properly cited.

\begin{abstract}
The classical Stackelberg game is extended to boundedly rational price Stackelberg game, and the dynamic duopoly game model is described in detail. By using the theory of bifurcation of dynamical systems, the existence and stability of the equilibrium points of this model are studied. And some comparisons with Bertrand game with bounded rationality are also performed. Stable region, bifurcation diagram, The Largest Lyapunov exponent, strange attractor, and sensitive dependence on initial conditions are used to show complex dynamic behavior. The results of theoretical and numerical analysis show that the stability of the price Stackelberg duopoly game with boundedly rational players is only relevant to the speed of price adjustment of the leader and not relevant to the follower's. This is different from the classical Cournot and Bertrand duopoly game with bounded rationality. And the speed of price adjustment of the boundedly rational leader has a destabilizing effect on this model.
\end{abstract}

\section{Introduction}

In the oligopolistic market, oligopoly firms compete in quantity or price. We all know that Cournot model [1] is one of the most famous quantity game models, in which all firms (players) are provided with naive expectations. Presently, boundedly rational quantity oligopoly game has been studied widely, and a player can choose his expectation rule from three different expectations: naive, bounded rational, and adaptive $[2,3]$. Many duopoly quantity games with homogeneous or heterogeneous players have been studied under linear or nonlinear demand function and linear or nonlinear cost functions [2-7]. Similarly, some researchers have studied all sorts of triopoly quantity game models [8-13]. These studies find that there are some complex dynamic behaviors such as bifurcation and chaos in the oligopoly quantity game model.

Compared with quantity competition, maybe price competition is more general in a real market. One of the most classical price game models is the Bertrand model [14]. In Bertrand model, each firm will try to reduce its product price, until its products are selling at no profit. This result is called Bertrand paradox. However, the Bertrand paradox rarely appears in practice. One of the reasons is that completely homogeneous product is almost nonexistent. So, one way of avoiding the paradox is to allow the firms to sell differentiated products [15]. Similar to quantity competition, boundedly rational duopoly and triopoly price game models with differentiated products have been studied in [16-19].

In the above mentioned quantity and price game models, the one-short games are static; that is, each of the players in the game determines their quantity or price at the same time. However, dynamic game or sequential game is very common in the real market. We all know that the most classical sequential game is Stackelberg game $[20,21]$ in which one firm, the leader, commits to a strategy first and publicly, and then the remaining firms, the followers, observe the leader's choice and make their decisions. The original Stackelberg game model is a quantity game with homogeneous product. Later, it was extended to the differentiated products for both quantity and price game. Vives [22] summarized the literature about the Stackelberg game model and pointed out that the relevant literature took the quantity for decision variable mostly. Until now there is little literature on price Stackelberg 
game. Consequently, there is no result for boundedly rational price Stackelberg in a differentiated products market. And its dynamic has not been studied. This paper aims to fill this gap.

This paper is organized as follows. In Section 2, the price Stackelberg duopoly game model with boundedly rational players is briefly described. The local stability condition of the equilibrium point is discussed in Section 3. In Section 4, numerical simulations are used to demonstrate the complex dynamics of our model. Finally, the conclusion of this paper is provided in Section 5.

\section{The Model}

We consider an oligopoly market served by two firms producing differentiated products. The two firms compete in price. Firm 1, as the leader, chooses a price $p_{1}$ first, and firm 2 , as the follower, observes $p_{1}$ then chooses a price $p_{2}$. Let $p_{i}(n)$ denote the price of $i$ th firm, $i=1,2$ during period $n=0,1,2, \ldots$. The quantity each firm sells $Q_{i}$, a linear inverse demand function, is determined by the following equations $[15,21]$ :

$$
\begin{aligned}
& Q_{1}=a-b p_{1}+d p_{2}, \\
& Q_{2}=a-b p_{2}+d p_{1},
\end{aligned}
$$

where $a>0, b>0, d>0$, and $b>d$. The parameter $d$ reflects the extent to which the two differentiated products are substitutes for each other. The cost function has the linear form:

$$
C_{i}=c_{i} Q_{i}, \quad i=1,2,
$$

where $c_{i}$ is the marginal cost of $i$ th firm, so $c_{i}$ is a positive constant.

At the second stage of the period $t$, firm 2 observes $p_{1}(n)$ then chooses a price $p_{2}(n)$ to maximize its own profits. Thus, the profit of the follower is given by

$$
\begin{aligned}
\Pi_{2}(n) & =\left(p_{2}(n)-c_{2}\right) Q_{2}(n) \\
& =\left(p_{2}(n)-c_{2}\right)\left(a-b p_{2}(n)+d p_{1}(n)\right) .
\end{aligned}
$$

The marginal profit of the firm 2 is

$$
\frac{\partial \Pi_{2}(n)}{\partial p_{2}(n)}=a+b c_{2}-2 b p_{2}(n)+d p_{1}(n) .
$$

Setting $\partial \Pi_{2}(n) / \partial p_{2}(n)=0$, the profit-maximizing price for firm 2 is obtained as follow:

$$
p_{2}(n)=\frac{a+b c_{2}+d p_{1}(n)}{2 b} .
$$

At the first stage of the period $n$, the leader's profit is given by

$$
\begin{aligned}
\Pi_{1}(n) & =\left(p_{1}(n)-c_{1}\right) Q_{1}(n) \\
& =\left(p_{1}(n)-c_{1}\right)\left(a-b p_{1}(n)+d p_{2}(n)\right) .
\end{aligned}
$$

Since firm 1 predicts that firm 2 chooses its optimum price $p_{2}(n)$ in terms of (5), then substituting (5) into (6), we get

$$
\Pi_{1}(n)=\left(p_{1}(n)-c_{1}\right)\left(a-b p_{1}(n)+d \frac{a+b c_{2}+d p_{1}(n)}{2 b}\right) .
$$

So, the marginal profit of the firm 1 is

$$
\begin{aligned}
\frac{\partial \Pi_{1}(n)}{\partial p_{1}(n)}= & a-\left(2 b-\frac{d^{2}}{b}\right) p_{1}(n) \\
& +\frac{a d+2 b^{2} c_{1}+b c_{2} d-c_{1} d^{2}}{2 b} .
\end{aligned}
$$

In this work, the two firms (leader and follower) are boundedly rational players. They have no complete information of market, and they determine the price of production with the information of local profit maximization.

The leader determines its price of production of period $n+1$ on the basis of expected marginal profit $\partial \Pi_{1}(n) / \partial p_{1}(n)$. The leader will increase (decrease) its price for period $n+1$ if the marginal profit is positive (negative) at period $n$. This adjustment mechanism has been called myopic by Dixit in [23]. Thus, this dynamical mechanism can be modeled as

$$
p_{1}(n+1)=p_{1}(n)+\alpha_{1} p_{1}(n) \frac{\partial \Pi_{1}(n)}{\partial p_{1}(n)},
$$

where $\alpha_{1}$ is a positive parameter and represents the speed of adjustment of the leader. Substituting (8) into (9), the dynamical adjustment mechanism of the leader (firm 1) has the following form:

$$
\begin{aligned}
p_{1}(n+1)=p_{1}(n)+\alpha_{1} p_{1}(n)( & a-\left(2 b-\frac{d^{2}}{b}\right) p_{1}(n) \\
+ & \left.\frac{a d+2 b^{2} c_{1}+b c_{2} d-c_{1} d^{2}}{2 b}\right) .
\end{aligned}
$$

The follower is also a boundedly rational player and changes its price according to its marginal profit $\partial \Pi_{2} / \partial p_{2}$. But, based on the above definition, the follower has known the current production price of the leader when it chooses its production. Hence, it is unreasonable if the follower determines its production price of period $n+1$ on the basis of marginal profit of period $n\left(\partial \Pi_{2}(n) / \partial p_{2}(n)\right)$. In this work, we assume the follower decides the $p_{2}(n+1)$ according to a forecasting marginal profit of current period. We define it as $\partial \Pi_{2}^{\text {forecast }}(n+1) / \partial p_{2}(n+1)$. By using $(4)$, we have

$$
\frac{\partial \Pi_{2}^{\text {forecast }}(n+1)}{\partial p_{2}(n+1)}=a+b c_{2}-2 b p_{2}(n+1)+d p_{1}(n+1) \text {. }
$$

Then the dynamical equation of the follower can be modeled as

$$
p_{2}(n+1)=p_{2}(n)+\alpha_{2} p_{2}(n) \frac{\partial \Pi_{2}^{\text {forecast }}(n+1)}{\partial p_{2}(n+1)},
$$

where $\alpha_{2}$ is also a positive parameter and represents the adjustment speed of the follower.

Substituting (11) into (12), we have

$$
\begin{aligned}
p_{2}(n+1)= & p_{2}(n)+\alpha_{2} p_{2}(n) \\
& \times\left(a+b c_{2}-2 b p_{2}(n+1)+d p_{1}(n+1)\right) .
\end{aligned}
$$


By solving (13), it can be reduced to

$$
p_{2}(n+1)=\frac{p_{2}(n)}{1+2 \alpha_{2} b p_{2}(n)}\left(1+\alpha_{2}\left(a+b c_{2}+d p_{1}(n+1)\right)\right) \text {. }
$$

Thus, the price Stackelberg duopoly game with boundedly rational players is described by the following twodimensional discrete dynamical system:

$$
\begin{array}{r}
p_{1}(n+1)=p_{1}(n)+\alpha_{1} p_{1}(n)\left(a-\left(2 b-\frac{d^{2}}{b}\right) p_{1}(n)\right. \\
\left.+\frac{a d+2 b^{2} c_{1}+b c_{2} d-c_{1} d^{2}}{2 b}\right), \\
p_{2}(n+1)=\frac{p_{2}(n)}{1+2 \alpha_{2} b p_{2}(n)}\left(1+\alpha_{2}\left(a+b c_{2}+d p_{1}(n+1)\right)\right) .
\end{array}
$$

One can see that the form of this dynamical system is so different from the previous classical Cournot and Bertrand duopoly game with bounded rationality. And the product price of the leader at period $n+1$ is only relevant to its own price of period $n$; but the product price of the follower at period $n+1$ is determined by its own price of period $n$ and the leader's price of period $n+1$. In addition, this model is unsymmetrical and this is different from the Zhang's [16] and Peng's model, [19], in which their models are symmetrical. Maybe these will give rise to different result and complicated dynamics from the boundedly rational Cournot and Bertrand duopoly game.

\section{Equilibrium Points and Local Stability}

We are interested only in nonnegative trajectories; hence, the system is not defined in the origin $(0,0)$. By setting $p_{i}(n+1)=$ $p_{i}(n)=p_{i}$ in the dynamical system (15), we get the following nonlinear algebraic system:

$$
\begin{gathered}
\alpha_{1} p_{1}\left(a-\left(2 b-\frac{d^{2}}{b}\right) p_{1}+\frac{a d+2 b^{2} c_{1}+b c_{2} d-c_{1} d^{2}}{2 b}\right)=0, \\
\frac{p_{2}}{1+2 \alpha_{2} b p_{2}}\left(1+\alpha_{2}\left(a+b c_{2}+d p_{1}\right)\right)-p_{2}=0 .
\end{gathered}
$$

It is easy to work out two fixed points:

$$
\begin{gathered}
E_{1}=\left(\frac{2 a b+a d+2 b^{2} c_{1}+b c_{2} d-c_{1} d^{2}}{4 b^{2}-2 d^{2}}, 0\right), \\
E^{*}=\left(p_{1}^{*}, p_{2}^{*}\right),
\end{gathered}
$$

where

$$
\begin{gathered}
p_{1}^{*}=\frac{2 a b+a d+2 b^{2} c_{1}+b c_{2} d-c_{1} d^{2}}{4 b^{2}-2 d^{2}} \\
p_{2}^{*}=\frac{4 a b^{2}+2 a b d+2 b^{2} c_{1} d+4 b^{3} c_{2}-a d^{2}-b c_{2} d^{2}-c_{1} d^{3}}{2 b\left(4 b^{2}-2 d^{2}\right)}
\end{gathered}
$$

Obviously, $E_{1}$ is a boundary equilibrium. The fixed point $E^{*}$ is the Nash equilibrium and has economic sense due to $b>d$.

Easily, we can get the following:

$$
\begin{aligned}
p_{1}^{*}-p_{2}^{*}=( & 2 b^{2} d\left(c_{2}-c_{1}\right)+4 b^{3}\left(c_{1}-c_{2}\right) \\
& \left.-2 b c_{1} d^{2}+a d^{2}+b c_{2} d^{2}+c_{1} d^{3}\right) \\
\times & \left(2 b\left(4 b^{2}-2 d^{2}\right)\right)^{-1}
\end{aligned}
$$

For comparison, setting $c_{1}=c_{2}=c$, then we have

$$
p_{1}^{*}-p_{2}^{*}=\frac{d^{2}(a-b c+c d)}{2 b\left(4 b^{2}-2 d^{2}\right)}
$$

The quantity $Q_{1}=Q_{2}=a-b c+c d>0$ when price $p_{1}=p_{2}=$ $c$, so $p_{1}^{*}>p_{2}^{*}$. That is to say, in Nash equilibrium the leader's product price is always greater than follower's product price.

In addition, we remember that in Zhang's model [16] the product price of firm 1 in the Nash equilibrium is

$$
p_{1}^{*}=\frac{2 a b+a d+2 b^{2} c_{1}+b c_{2} d}{4 b^{2}-d^{2}} .
$$

Obviously, $p_{1}^{*}$ of our model is less than $p_{1}^{*}$ of Zhang's model. (This is comparable because there are the same inverse demand functions and linear cost functions in our model and Zhang's model.) This is beneficial for consumers.

In order to investigate the local stability of the equilibrium points of $E_{1}$ and $E^{*}$, we return to the two-dimensional dynamical system. Let $J$ be the Jacobian matrix of the system corresponding to the state variables $\left(q_{1}, q_{2}\right)$ then

$$
J\left(p_{1}, p_{2}\right)=\left[\begin{array}{cc}
A_{1} & 0 \\
\frac{\alpha_{2} d p_{2} A_{1}}{1+2 \alpha_{2} b p_{2}} & \frac{1+\alpha_{2}\left(a+b c_{2}+d A_{2}\right)}{\left(1+2 \alpha_{2} b p_{2}\right)^{2}}
\end{array}\right],
$$

where

$$
\begin{array}{r}
A_{1}=1+\alpha_{1}\left(a-2\left(2 b-\frac{d^{2}}{b}\right) p_{1}\right. \\
\left.+\frac{a d+2 b^{2} c_{1}+b c_{2} d-c_{1} d^{2}}{2 b}\right), \\
A_{2}=p_{1}+\alpha_{1} p_{1}\left(a-\left(2 b-\frac{d^{2}}{b}\right) p_{1}\right. \\
\left.+\frac{a d+2 b^{2} c_{1}+b c_{2} d-c_{1} d^{2}}{2 b}\right) .
\end{array}
$$

The stability of equilibrium points will be determined by the nature of the eigenvalues of the Jacobian matrix evaluated at the corresponding equilibrium points.

Theorem 1. The boundary equilibrium point $E_{1}$ of the system (15) is unstable. 
Proof. The Jacobian matrix at $E_{1}$ takes the form:

$$
\begin{aligned}
& J\left(E_{1}\right) \\
& =\left[\begin{array}{cc}
1-\alpha_{1} \frac{2 a b+a d+2 b^{2} c_{1}+b c_{2} d-c_{1} d^{2}}{2 b} & 0 \\
0 & 1+\alpha_{2}\left(a+b c_{2}+d p_{1}\right)
\end{array}\right] .
\end{aligned}
$$

Its eigenvalues are

$$
\begin{gathered}
\lambda_{1}=1-\alpha_{1} \frac{2 a b+a d+2 b^{2} c_{1}+b c_{2} d-c_{1} d^{2}}{2 b}, \\
\lambda_{2}=1+\alpha_{2}\left(a+b c_{2}+d p_{1}\right) .
\end{gathered}
$$

Since $a>0, b>0, c_{i}>0(i=1,2)$ and $b>d$, so we have that $\left|\lambda_{1}\right|<1$ and $\left|\lambda_{2}\right|>1$. Then $E_{1}$ is a saddle point of discrete dynamical system (15). This completes the proof of the Theorem 1.

Next, we will investigate the local stability of the Nash equilibrium point $E^{*}$.

3.1. Local Stability of Nash Equilibrium Point $E^{*}$. The Jacobian matrix at $E^{*}$ takes the form:

$$
\begin{aligned}
& J\left(E^{*}\right) \\
& =\left[\begin{array}{cc}
1-\alpha_{1}\left(2 b-\frac{d^{2}}{b}\right) p_{1}^{*} & 0 \\
\frac{\alpha_{2} d p_{2}^{*}\left(1-\alpha_{1}\left(2 b-d^{2} / b\right) p_{1}^{*}\right)}{1+2 \alpha_{2} b p_{2}^{*}} & \frac{1}{1+2 \alpha_{2} b p_{2}^{*}}
\end{array}\right] .
\end{aligned}
$$

Its eigenvalues are

$$
\begin{gathered}
\lambda_{1}=1-\alpha_{1}\left(2 b-\frac{d^{2}}{b}\right) p_{1}^{*}, \\
\lambda_{2}=\frac{1}{1+2 \alpha_{2} b p_{2}^{*}} .
\end{gathered}
$$

If the eigenvalues $\lambda_{i}, i=1,2$, satisfy inequalities $\left|\lambda_{i}\right|<1, i=$ 1,2 , then the Nash equilibrium points will be locally stable. First, $\left|\lambda_{i}\right|<1$ that is

$$
\left|1-\alpha_{1}\left(2 b-\frac{d^{2}}{b}\right) p_{1}^{*}\right|<1 .
$$

It can be reduced to

$$
0<\alpha_{1}<\frac{2}{\left(2 b-d^{2} / b\right) p_{1}^{*}}
$$

Substituting $p_{1}^{*}$, we have

$$
0<\alpha_{1}<\frac{4 b}{2 a b+a d+2 b^{2} c_{1}+b c_{2} d-c_{1} d^{2}} .
$$

Then $\left|\lambda_{2}\right|<1$ equal to $\left|1 /\left(1+2 \alpha_{2} b p_{2}^{*}\right)\right|<1$. This inequality is always fulfilled due to $\alpha_{2}, b$, and $p_{2}^{*}>0$.

So, we can state the following summarizing result.

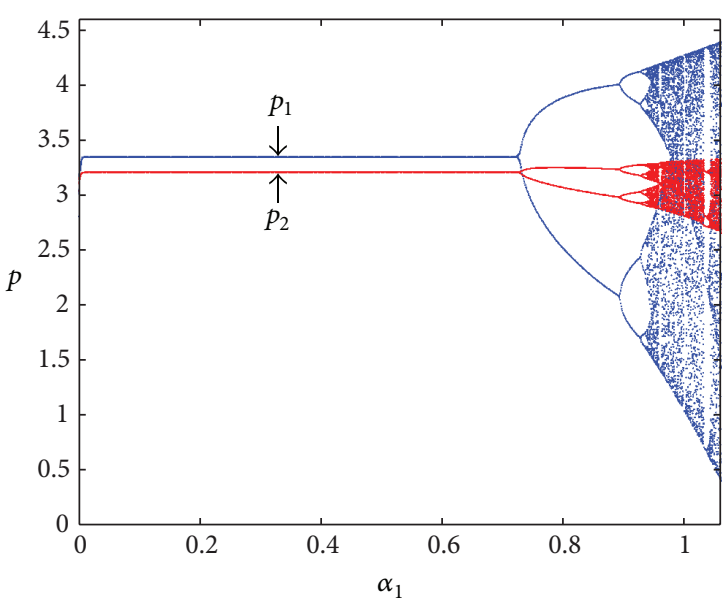

FIGURE 1: Bifurcation diagram with respect to $\alpha_{1}$ when $\alpha_{2}=0.5$.

Theorem 2. The Nash equilibrium $E^{*}$ of the dynamical system (15) is locally asymptotically stable provided that

$$
0<\alpha_{1}<\frac{4 b}{2 a b+a d+2 b^{2} c_{1}+b c_{2} d-c_{1} d^{2}} .
$$

The inequality (31) defines a range in which the Nash equilibrium point $E^{*}$ is stable; otherwise the Nash equilibrium point $E^{*}$ loses its stability through the boundary of this range. And one can conclude that the stability of the dynamical system (15) is only relevant to the adjustment speed of the leader and not relevant to the follower's adjustment speed. This result is significant and different from the classical Cournot and Bertrand duopoly game with bounded rationality. In addition, one can see, stability region of the Nash equilibrium point is a decreasing function with respect to the market capacity $a$ and the marginal cost $c_{1}$.

These inferences will be demonstrated in Section 4 .

\section{Numerical Simulations}

In order to be more clear and intuitive in understanding the complex dynamic behavior of the discrete dynamical system (15), numerical analysis is used to describe the dynamical evolution process. For convenience, we take $a=2, b=0.5$, $c_{1}=0.2, c_{2}=0.4, d=0.3$ to study the local stability properties of the Nash equilibrium point. By calculation, we get the Nash equilibrium $E^{*}=(3.3439,3.2032)$.

Figure 1 shows the price bifurcation diagram with respect to $\alpha_{1}$ (the adjustment speed of boundedly rational leader) of dynamical system (15) when $\alpha_{2}=0.5$. One can see the Nash equilibrium $E^{*}=(3.3439,3.2032)$ is locally stable when the parameter $\alpha_{1}$ is small. As $\alpha_{1}$ increases, the Nash equilibrium point becomes unstable; that is, Period-2 and period-4 bifurcations appear and finally chaotic scenario occur. Definitely, when $\alpha_{1}>0.7294$, flip (period-doubling) bifurcation occurs and complex dynamic behavior begins to appear. Obviously, this fluctuation of system is harmful to both firms. One can conclude that the speed of adjustment 


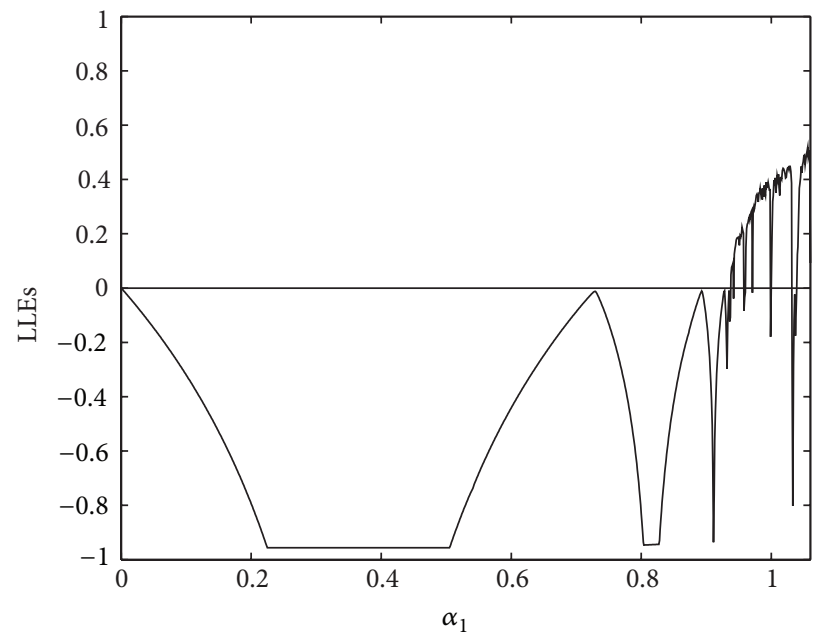

FIGURE 2: The largest Lyapunov exponent versus $\alpha_{1} \in[0,1.06]$ for $\alpha_{2}=0.5$.

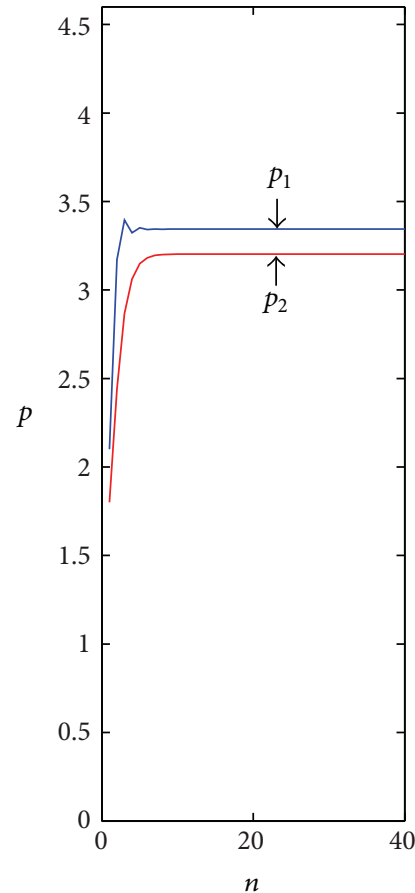

(a)

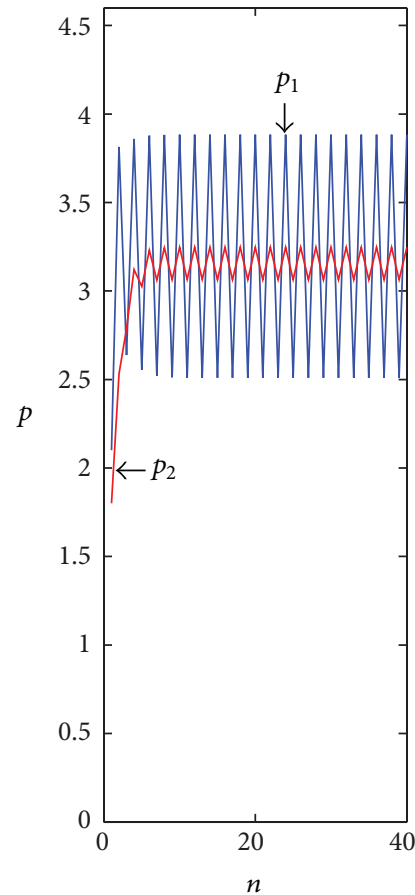

(b)

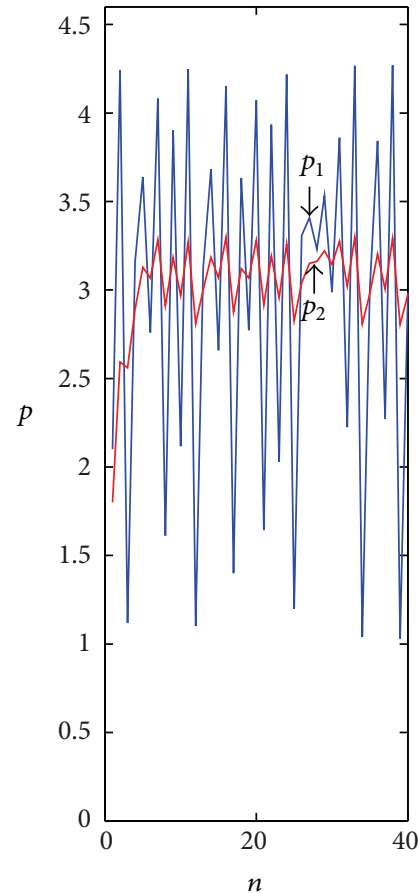

(c)

FIGURE 3: Time sequence diagrams under different states.

of the boundedly rational leader $\alpha_{1}$ has a destabilizing effect to the dynamical system (15). The Largest Lyapunov exponent which corresponds to Figure 1 is plotted in Figure 2. This diagram also shows the relationship between the local stability of the Nash equilibrium point and the speed of adjustment of the boundedly rational leader $\alpha_{1}$. And one can obtain a better understanding of dynamical behaviors of the system (15).

Figure 3 shows the price evolution with time when the dynamical system (15) is in the stable $\left(\alpha_{1}=0.5\right)$, perioddoubling bifurcations $\left(\alpha_{1}=0.8\right)$, and chaotic state $\alpha_{1}=1.0$.
As can be seen from Figure 3(a), along with the continuation of competitive cycle, the price of two firms will be stable in equilibrium state gradually after a series of fluctuation. And the price evolves into 2-period orbit gradually in Figure 3(b). But in Figure 3(c), the price is in chaos and takes on unordered change.

We draw the two-dimension flip bifurcation diagram in the parameters $\alpha_{1}$ and $a$ (Figure 4(a)) and $\alpha_{1}$ and $c_{1}$ (Figure 4(b)). In Figure 4, the Nash equilibrium is stable when the parameters $\alpha_{1}, a$, and $c_{1}$ are in the cyan-shaped area (stability region) and loses its stability with increasing value 


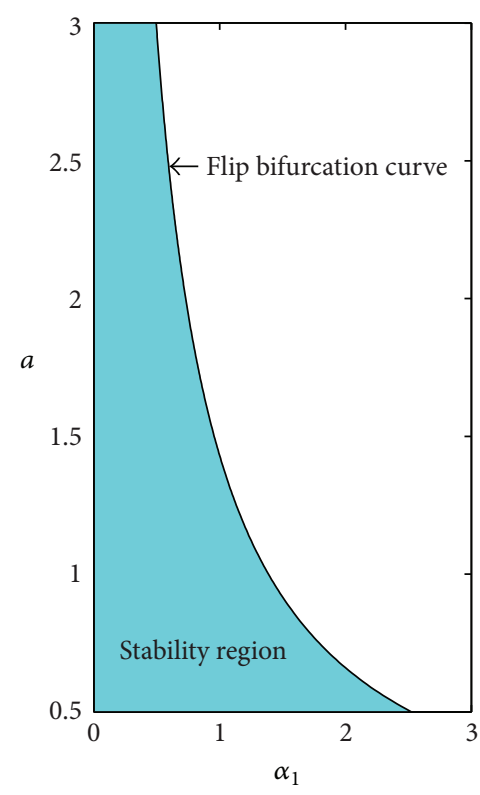

(a)

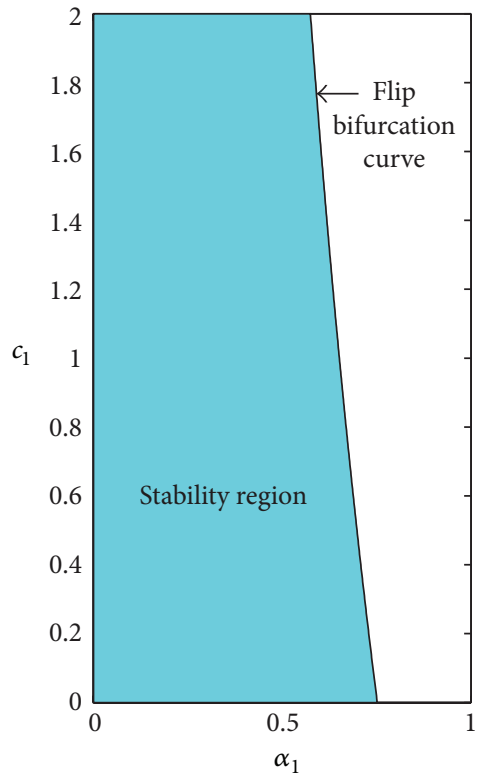

(b)

FIGURE 4: Flip bifurcation curves in the parameters $\alpha_{1}$ and $a$ (a) and $\alpha_{1}$ and $c_{1}$ (b).

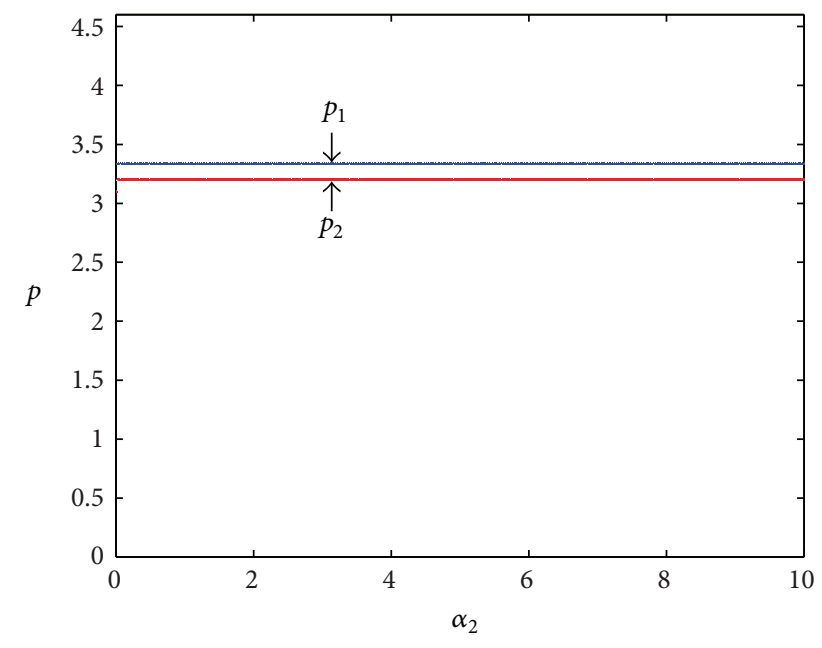

FIGURE 5: Evolution diagram with respect to $\alpha_{2}$ when $\alpha_{1}=0.5$.

of $\alpha_{1}$. And the two-flip bifurcation cures are inverse function cures. This demonstrates what was mentioned above that stability region of the Nash equilibrium point is a decreasing function with respect to the market capacity $a$ and the marginal cost $c_{1}$.

Figure 5 shows the price evolution process with respect to $\alpha_{2}$ (the speed of adjustment of the boundedly rational follower) of dynamical system (15) when $\alpha_{1}=0.5$. In Figure 4, the price is unalterable all the while and the dynamical system (15) is always locally stable. And this also demonstrates that the speed of adjustment of the boundedly rational follower has no effect on the game model.

Strange attractor is one of the main features of chaotic motion. It exhibits fractal structure. Figure 6 shows the

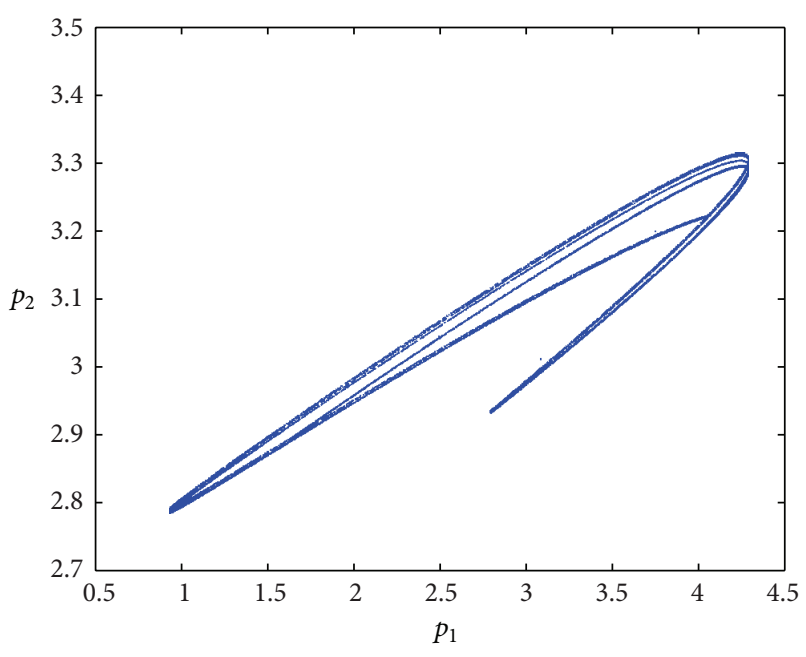

FIGURE 6: Strange attractor when $\alpha_{1}=1.01$ and $\alpha_{2}=0.5$.

strange attractor in the phase plane $\left(q_{1}, q_{2}\right)$ for the parameter values $a=2, b=0.5, c_{1}=0.2, c_{2}=0.4, \alpha_{1}=1.07$, and $\alpha_{2}=0.5$.

Sensitive dependence on initial conditions is another main characteristic of chaotic system. In order to demonstrate sensitive dependence on initial conditions of system (10), we simulate two orbits in Figure 7 for the parameter values $a=2, b=0.5, c_{1}=0.2, c_{2}=0.4, \alpha_{1}=1.01$, and $\alpha_{2}=0.5$. The red and blue curves start from the initial points $\left(p_{1}(0), p_{2}(0)\right)=(2.5,2.3)$ and $\left(p_{1}(0), p_{2}(0)\right)=$ $(2.5001,2.3)$, respectively. It shows that, at the beginning, they are indistinguishable, but after a number of iterations, the difference between them builds up rapidly. 


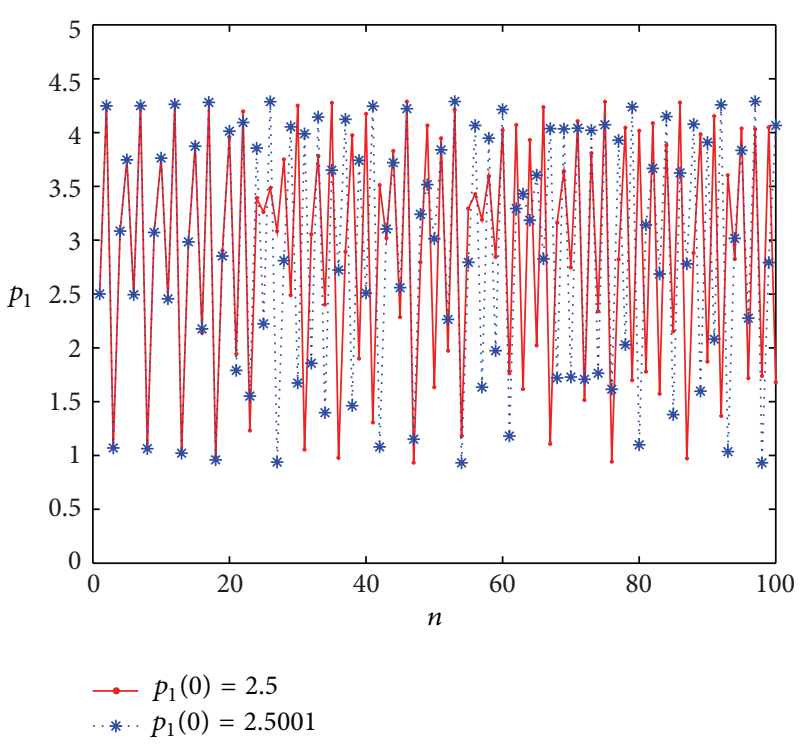

FIgURE 7: Shows sensitive dependence on initial conditions; the two orbits of $p_{1}$-coordinates for $\left(a, b, c_{1}, c_{2}, d, \alpha_{1}, \alpha_{2}\right)=$ $(2,0.5,0.2,0.4,0.3,1.01,0.5)$ with $\left(p_{1}(0), p_{2}(0)\right)=(2.5,2.3)$ for the red curve and $\left(p_{1}(0), p_{2}(0)\right)=(2.5001,2.3)$ for the blue curve.

\section{Conclusion}

In this paper we have proposed a price Stackelberg duopoly game model with boundedly rational players. The complex dynamical behaviors have been studied. In Nash equilibrium, the price of the leader is less than the follower's and also less than equilibrium price of Bertrand game under the same assumption. The theoretical and numerical analysis shows the result that the stability of the dynamical system (15) is only relevant to the speed of price adjustment of the boundedly rational leader and not relevant to the follower's. Definitely, the speed of price adjustment of the boundedly rational leader has a destabilizing effect and the follower's has no effect on the dynamical system. This is different from the classical Cournot and Bertrand duopoly game with bounded rationality. Perhaps the reason of this is the Stackelberg-type game structure. The other type of price Stackelberg game, such as with heterogeneous player or different competition strategies, will be studied in future work.

\section{Conflict of Interests}

The authors declare that there is no conflict of interests regarding the publication of this paper.

\section{Acknowledgments}

The authors would like to thank the anonymous referees very much for their valuable comments and suggestions. This work was supported by Major Program of National Natural Science Foundation of China (71390521 and 71390523) and by National Natural Science Foundation of China (71101067, 71271103, 71301062, and 71301070).

\section{References}

[1] A. Cournot, Recherches sur les Principes Mathématiques de la Théoris des Richesses, Hachette, Paris, France, 1838.

[2] H. N. Agiza and A. A. Elsadany, "Nonlinear dynamics in the Cournot duopoly game with heterogeneous players," Physica A, vol. 320, no. 1-4, pp. 512-524, 2003.

[3] H. N. Agiza and A. A. Elsadany, "Chaotic dynamics in nonlinear duopoly game with heterogeneous players," Applied Mathematics and Computation, vol. 149, no. 3, pp. 843-860, 2004.

[4] M. Kopel, "Simple and complex adjustment dynamics in Cournot duopoly models," Chaos, Solitons and Fractals, vol. 7, no. 12, pp. 2031-2048, 1996.

[5] J. X. Zhang, Q. L. Da, and Y. H. Wang, "Analysis of nonlinear duopoly game with heterogeneous players," Economic Modelling, vol. 24, no. 1, pp. 138-148, 2007.

[6] T. Dubiel-Teleszynski, "Nonlinear dynamics in a heterogeneous duopoly game with adjusting players and diseconomies of scale," Communications in Nonlinear Science and Numerical Simulation, vol. 16, no. 1, pp. 296-308, 2011.

[7] F. Tramontana, "Heterogeneous duopoly with isoelastic demand function," Economic Modelling, vol. 27, no. 1, pp. 350-357, 2010.

[8] T. Puu, "Complex dynamics with three oligopolists," Chaos, Solitons and Fractals, vol. 7, no. 12, pp. 2075-2081, 1996.

[9] H. N. Agiza, G. I. Bischi, and M. Kopel, "Multistability in a dynamic Cournot game with three oligopolists," Mathematics and Computers in Simulation, vol. 51, no. 1-2, pp. 63-90, 1999.

[10] A. Agliari, L. Gardini, and T. Puu, "The dynamics of a triopoly Cournot game," Chaos, Solitons and Fractals, vol. 11, no. 15, pp. 2531-2560, 2000.

[11] E. M. Elabbasy, H. N. Agiza, A. A. Elsadany, and H. El-Metwally, "The dynamics of triopoly game with heterogeneous players," International Journal of Nonlinear Science, vol. 3, no. 2, pp. 8390, 2007.

[12] E. M. Elabbasy, H. N. Agiza, and A. A. Elsadany, "Analysis of nonlinear triopoly game with heterogeneous players," Computers \& Mathematics with Applications, vol. 57, no. 3, pp. 488-499, 2009.

[13] H. X. Yao, L. Shi, and H. Xi, "Analysis of triopoly game with isoelastic demand function and heterogeneous players," Discrete Dynamics in Nature and Society, vol. 2012, Article ID 280824, 16 pages, 2012.

[14] J. Bertrand, "Théorie mathématique de la richesse sociale," Journal des Savants, pp. 499-508, 1883.

[15] H. Gravelle and R. Rees, Microeconomics, Longman, Harlow, UK, 2nd edition, 1992.

[16] J. X. Zhang, Q. L. Da, and Y. H. Wang, "The dynamics of Bertrand model with bounded rationality," Chaos, Solitons and Fractals, vol. 39, no. 5, pp. 2048-2055, 2009.

[17] B. G. Xin and T. Chen, "On a master-slave Bertrand game model," Economic Modelling, vol. 28, no. 4, pp. 1864-1870, 2011.

[18] F. Chen, J. H. Ma, and X. Q. Chen, “The study of dynamic process of the triopoly games in chinese $3 \mathrm{G}$ telecommunication market," Chaos, Solitons and Fractals, vol. 42, no. 3, pp. 15421551, 2009.

[19] J. Peng, Z. Miao, and F. Peng, "Study on a 3-dimensional game model with delayed bounded rationality," Applied Mathematics and Computation, vol. 218, no. 5, pp. 1568-1576, 2011.

[20] H. Stackelberg, Marketform und Gleichgewicht, Julius Springer, Vienna, Austria, 1934. 
[21] R. Gibbons, Game Theory for Applied Economists, Princeton University Press, Princeton, NJ, USA, 1992.

[22] X. Vives, Oligopoly Pricing: Old Ideas and New Tool, MIT Press, Cambridge, Mass, USA, 1999.

[23] A. Dixit, "Comparative statics for oligopoly," International Economic Review, vol. 27, no. 1, pp. 107-122, 1986. 


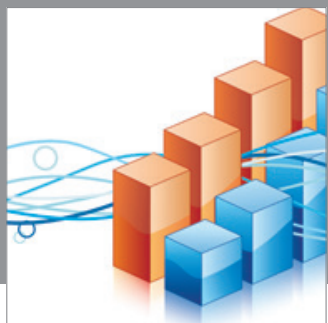

Advances in

Operations Research

mansans

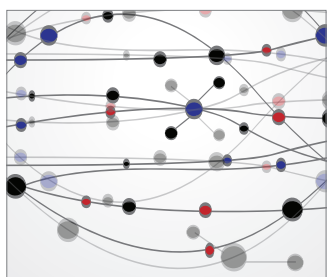

The Scientific World Journal
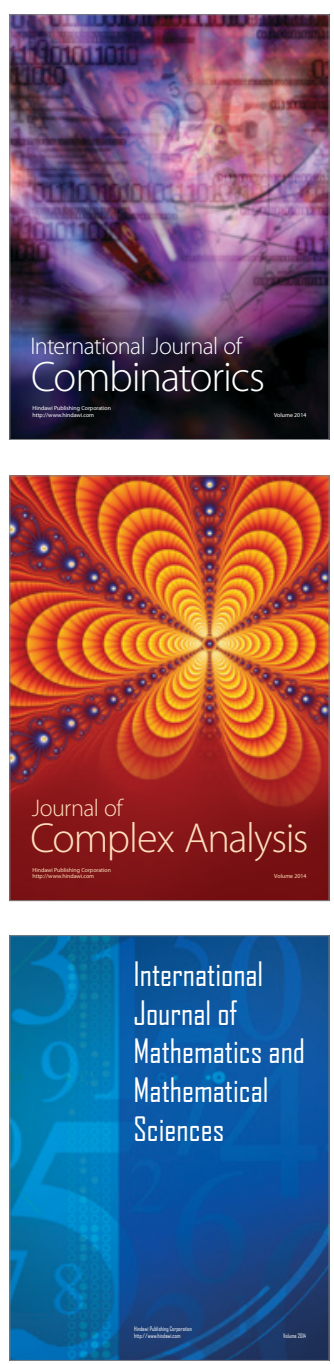
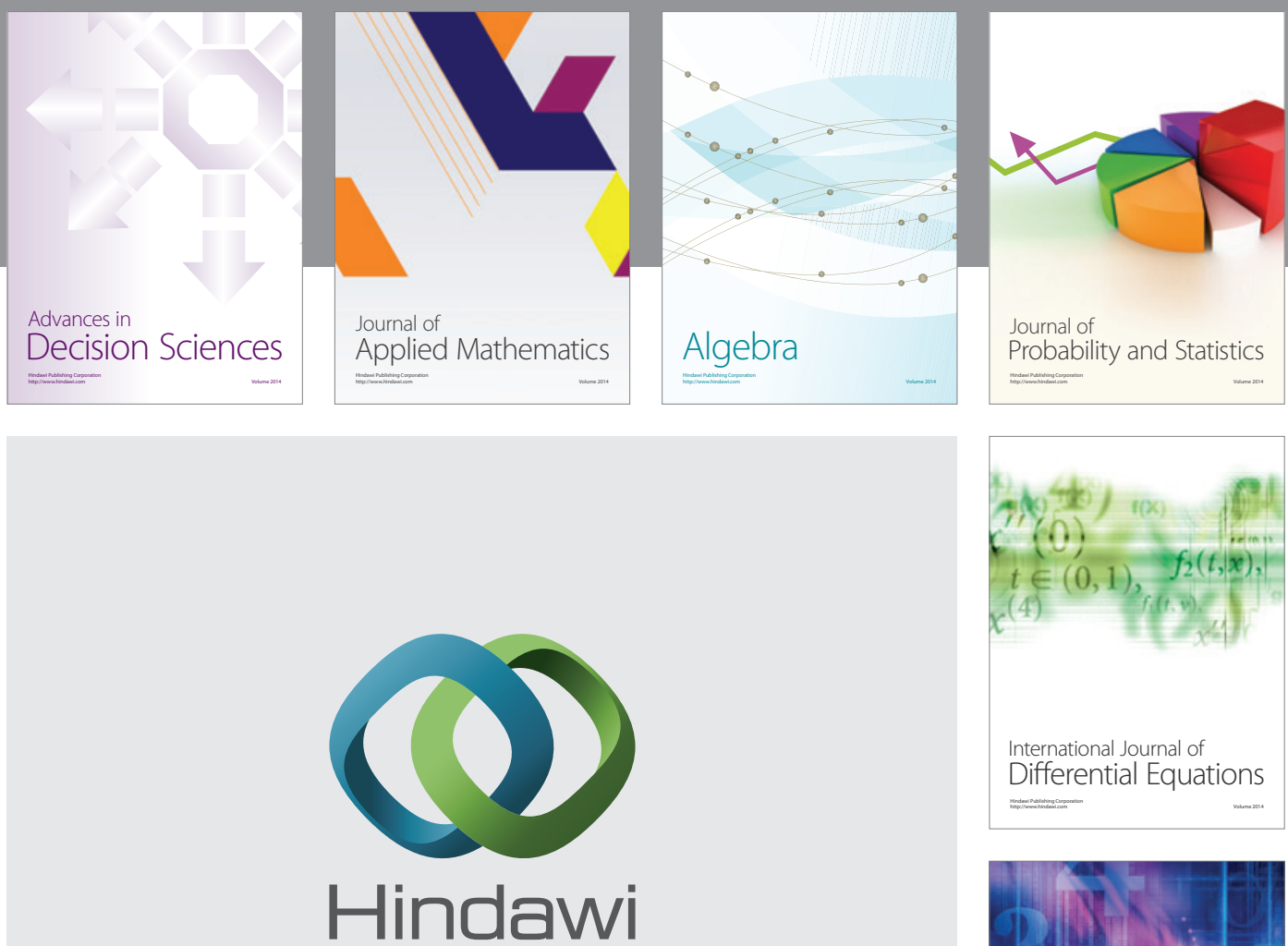

Submit your manuscripts at http://www.hindawi.com
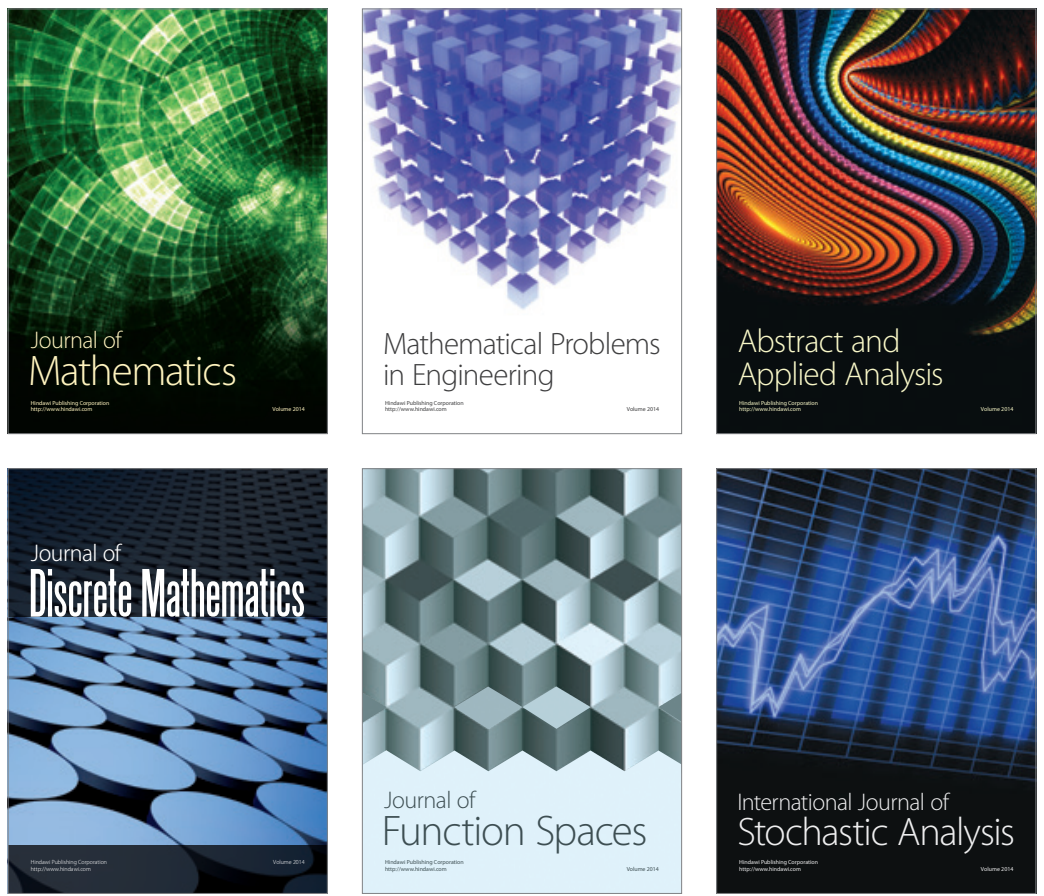

Journal of

Function Spaces

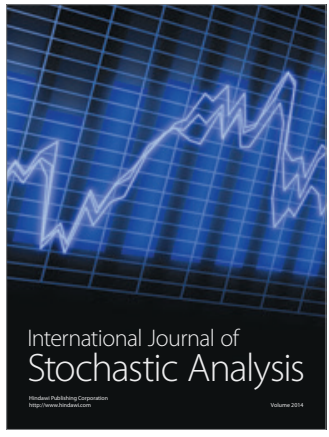

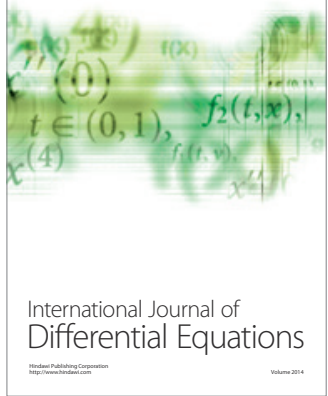
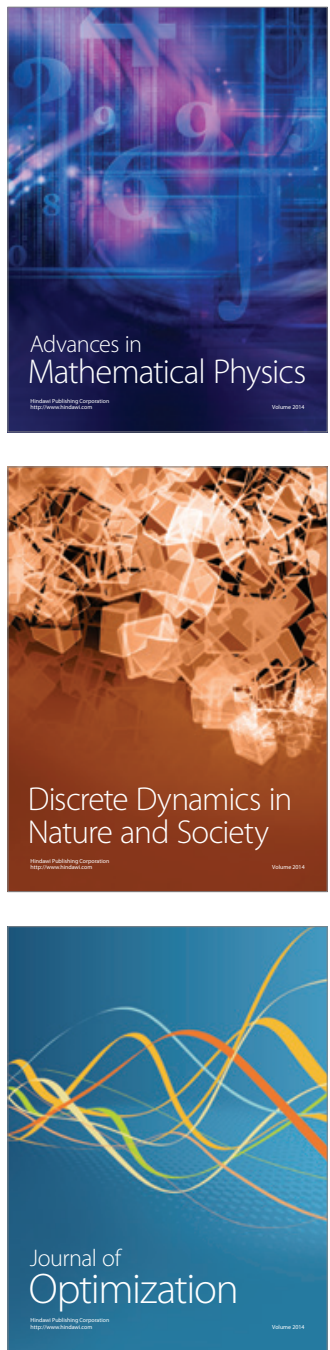